\title{
Response-contingent and non-contingent informative and redundant secondary reinforcers
}

\author{
DONALD F. MCCAUSLAND, GEORGE W. MENZER, THOMAS K. DEMPSEY AND JOHN C. BIRKIMER
}

UNIVERSITY OF LOUISVILLE

Eight albino rats were trained to bar-press for sucrose solution. After training procedures involving either responsecontingent or non-contingent pairings of two successive stimuli and reinforcement, the first temporal stimulus proved to be the stronger secondary reinforcer though temporally more distant from primary reinforcement during training. No difference was found between the two training methods, though previous successful and unsuccessful studies of the effect are dichotomized in this respect.

Jenkins (1950) and Bersh (1951) obtained results indicating that the strength of a secondary reinforcer $\left(S^{r}\right)$ is an inverse function of the time interval which separates it from primary reinforcement during training. Egger \& Miller (1962, 1963), however, have shown that when two stimuli precede reinforcement, it is the first temporal stimulus which acquires the greater $\mathbf{S}^{\mathbf{r}}$ strength, even though it is temporally more distant from reinforcement. Egger \& Miller pointed out that the first stimulus is informative with regard to reinforcement during training while the second is redundant, suggesting that $\mathbf{S}$ strength is dependent on information value.

Seligman (1966a) extended the Egger \& Miller finding to a punishment situation, demonstrating that the first of two stimuli preceding shock acquired the greater ability to suppress food-reinforced responding.

Two studies have failed to demonstrate greater $\mathrm{S}^{\mathbf{r}}$ strength for an informative stimulus compared to a redundant one. Armus, Guinan, Crowell, Schroeder, Rudge, \& Comtols (1964) reinforced rats for bar-pressing on a CRF schedule with a stimulus preceding each reinforcement and also on an FR-5 schedule with a different stimulus preceding reinforcement. After this training on a central bar, Ss were extinguished on two side bars. Pressing one of these produced the stimulus previously preceding CRF reinforcement, while pressing the other produced the FR-associated stimulus. Ss responded significantly more often on the bar producing the CRF stimulus. Armus et al argued that the CRF stimulus was redundant since it always followed informative proprioceptive feedback from bar-pressing, and thus should have been a weaker $S^{r}$ than the FR stimulus, the only informative stimulus preceding reinforcement on that schedule.

McKeever \& Forrin (1966) gave rats brightness discrimination training in a modified Grice maze. Ss learned to choose a black door followed by a black antechamber and then a white goalbox, instead of a gray door, antechamber, and goal box. (For half the
Ss black and white were reversed.) After reaching a nine out of 10 correct criterion on two successive days, Ss were given extinction testing in the maze, completely gray except that for half the Ss the previously reinforced black (or white) antechamber served as one goal box and, for the other half of the Ss, the previously reinforced white (or black) goal box served as one goal box. The mean percent runs to the critical side for the two groups differed from chance but were nearly identical, providing no evidence that the brightness of the antechamber, prior temporally to the goal box in training and thus informative, was a more powerful $\mathrm{S}^{\mathbf{r}}$ than the brightness of the goal box.

Both the Armus et al and the McKeever \& Forrin studies used designs in which the pairings of stimuli and reinforcement during training were response-contingent, while pairings were non-contingent in the Egger \& Miller and the Seligman studies. The present study, then, compares response-contingent and non-contingent pairing procedures.

Though the original Egger \& Miller study used both between- and within-subject comparisons of $\mathrm{S}^{\mathbf{r}}$ strength, the Seligman extension used a between-subjects design. The Armus et al study failed to replicate the effect in a within-subject test situation, while Armus \& Garlich (1961), using a procedure similar to that of Armus et al but with a between-subjects comparison, obtained results consistent with the Egger \& Miller findings. Given the contradictory results from the between and within designs in the two Armus studies, the present study also attempted to replicate the Egger \& Miller effect in a within-subject design.

Method

Ss were eight naive male Sprague-Dawley albino rats approximately 150-200 days old. Ss were trained at $80 \%$ ad lib weight and approximately $22 \mathrm{~h}$ food deprivation.

Two commercially manufactured operant conditioning chambers were used and a dipper administered $.01 \mathrm{cc}$ of $50 \%$ sucrose solution as reinforcement. White noise and the houselight in the chamber were used as stimuli, and all events were controlled by automatic programming equipment.

Each training session lasted $1 \mathrm{~h}$. On the first day, all Ss were given magazine training with the bar operative on a CRF schedule. Those Ss not spontaneously learning to bar-press were shaped to do so on the same day. All Ss then received two days of CRF training. Half the Ss were then given three sessions of VI-60 sec training with response-contingent pairings 
of the two stimuli and reinforcement. The other half of the Ss were also given three session of VI training with response-contingent reinforcement but no stimuli presented, then three sessions with the bar removed and the two stimuli and reinforcement presented without responding on the VI schedule. During all stimulus presentations, the first stimulus $\left(S_{1}\right)$ was presented for $2 \mathrm{sec}$, the second stimulus was then presented for $2 \mathrm{sec}$, and then reinforcement was given. The stimulus used as $s_{1}$, noise or light, was balanced within each treatment group.

The extinction testing session consisted of a series of $60 \mathrm{sec}$ intervals during which either $S_{1}$ and $S_{2}$ was produced for $2 \mathrm{sec}$ by each bar-press. Intervals were counterbalanced, in terms of the stimulus produced, in ABBA order. Testing was continued to a criterion of no responses in $5 \mathrm{~min}$.

\section{Results and Discussion}

An analysis of variance was run on a number of responses to each stimulus during testing. A significant effect of stimulus position was obtained ( $F=11.47$, $\mathrm{df}=1 / 6, \mathrm{p}<.02$ ). The first temporal stimulus was the stronger $\mathbf{S}^{\mathrm{r}}$; thus, the Egger \& Miller effect withinsubjects was replicated. No interaction was found between training method and stimulus position $(F<1.0)$, suggesting that the Egger and Miller effect holds whether or not the secondary reinforcers are responsecontingent during training. The control test comparing noise and light, balanced for positions as $S_{1}$ and $S_{2}$, yielded $t=.12(d f=7)$, indicating no effect of stimulus identity.

The results of this study, then, replicate the Egger \& Miller finding that the first of two stimuli preceding primary reinforcement gains the greater $\mathrm{S}^{\mathbf{r}}$ strength, and that the effect does hold when the same $S$ is exposed to both stimuli during testing. The study further shows that the use of response-contingent stimulus and reinforcement pairings in the Armus et al and the McKeever and Forrin studies does not account for their failure to obtain the Egger and Miller effect.

CRF schedules are obviously more reinforcing than FR schedules. If the $\mathbf{S}^{\mathbf{r}} \mathbf{s}$ involved in the Armus et al procedure are also discriminative stimuli with respect to the schedule they are paired with, then another variable, akin to amount of reward, would affect $\mathbf{S}^{r}$ strength in this situation.

The McKeever and Forrin study has been criticized on conceptual grounds by Seligman (1966b). (See also the reply by Forrin (1966).) It might be added that, for an animal performing at a $90 \%$ correct level, being placed in the start box may be a reliable enough predictor of reinforcement to render all later stimuli redundant. Further, the similarity of the two groups' scores may suggest that they were primarily avoiding the previously incorrect gray goal box.

An interesting parallel to the Egger and Miller effect appears in the literature on GSR conditioning. Wickens, Gehman, \& Sullivan (1959) and Wickens, Born, \& Wickens (1963) have found that, with two sequential stimuli preceding shock, the first of the two gains the greater control over the CR if the temporal arrangement of the two stimuli and the shock is appropriate. The possibility of predicting the Egger and Miller result from the classical conditioning literature and a CR theory of secondary reinforcement is apparent.

\section{References}

Armus, H. L., \& Garlich, M. M. Secondary reinforcement strength as a function of schedule of primary reinforcement. $J$, comp. physiol. Psychol., 1961, 54, 56-58.

Armus, H. L., Guinan, J. F., Crowell, R. A., Schroeder, S. R., Rudge, J. A., \& Comtois, D. R. Secondary reinforcement strength and primary reinforcement schedule: Single gr oup technique. $J$. comp. physiol. Psychol., 1964, 57, 313-315.

Bersh, P. J. The influence of two variables upon the establishment of a secondary reinforcer for operant responses. J. exp. Psychol., 1951, 41, 62-73.

Egger, M. D., \& Miller, N. E. Secondary reinforcement in rats as a function of information value and reliability of the stimulus. J. exp. Psychol., 1962, 64, 97-104.

Egger, M. D., \& Miller, N. E. When is reward reinforcing?: An experimental study of the information hypothesis. J. comp. physiol. Psychol, , 1963, 56, 132-137.

Forrin, B. Secondary reinforcing properties of informative and non-informative stimuli: Reply to Seligman. Psychon. Sci., 1966, 5,300 .

Jenkins, W. O. A temporal gradient of derived reinforcement. Amer. J. Psychol., 1950, 63, 237-243.

Mckeever, B., \& Forrin, B. Secondary reinforcing properties of informative and non-informative stimuli. Psychon. Sci., 1966 4, $115-116$.

Seligman, M. E. P. CS redundancy and secondary punishment. $J$. exp. Psychol., 1966a, 72, 546-550.

Seligman, M. E. P. Comment on McKeever and Forrin. Psychon. Sci., 1966b, 5, 299

Wickens, D. D., Born, D. G., \& Wickens, C. D. Response strength to a compound conditioned stimulus and its elements as a function of the element interstimulus interval. J. comp. physiol. Psychol., 1963, 56, 727-731.

Wickens, D. D., Gehman, R. S., \& Sullivan, S. N. The effect of differential onset time on the conditioned response strength to elements of a stimulus complex. J. exp. Psychol., 1959, 58, 85-93. 